\title{
Efficacy of Intramammary Tilmicosin and Risk Factors for Cure of Staphylococcus aureus Infection in the Dry Period
}

\author{
R. T. Dingwell, ${ }^{*}$ K. E. Leslie, ${ }^{*}$ T. F. Duffield, ${ }^{*}$ Y. H. Schukken, $\dagger$ \\ L. DesCoteaux,‡ G. P. Keefe,§ D. F. Kelton, ${ }^{*}$ K. D. Lissemore, ${ }^{\star}$ \\ W. Shewfelt, $\|$ P. Dick,\# and R. Bagg\# \\ *University of Guelph, Guelph, Ontario N1G 2W1, Canada \\ †Quality Milk Promotion Services, Cornell Univesity, Ithaca New York 14850-1263 USA \\ fUniversity of Montreal, St. Hyacinthe, Quebec J2S 7C6 Canada \\ §University of Prince Edward Island, Charlottetown, P.E.I. C1A 4P3 Canada \\ ||Tavistock Veterinarians, 25 Hope St. East Tavistock, Ontario, NOB 2R0 \\ \#Provel, Division of Eli Lilly Canada Inc., Research Park Centre, Guelph, Ontario N1G 4T2 Canada
}

\section{ABSTRACT}

The objective of this study was to evaluate the efficacy of intramammary tilmicosin, administered at dryingoff, for eliminating Staphylococcus aureus infection, and to identify risk factors for $S$. aureus cure during the dry period. A total of 219 naturally infected cows, representing 308 quarters, were randomized to receive either one of two treatments at drying-off. Cows received either an intramammary infusion of $500 \mathrm{mg}$ of benzathine cloxacillin, or a sterile solution containing $1500 \mathrm{mg}$ of tilmicosin. All cows had quarter milk samples taken aseptically three times before dry-off, and at wk 1, 2, and 4 of the subsequent lactation. Overall, $62 \%$ of cows and $67.5 \%$ of quarters infected with $S$. aureus cured during the dry period. The cure following administraton of tilmicosin was 67.3 and $72.5 \%$ for cows and quarters, respectively. By comparison, the cure achieved with cloxacillin was 56.9 and $62.9 \%$ of cows and quarters. Cows receiving tilmicosin were 2.1 times more likely to cure. The cure rate for cows decreased as the linear score on the last DHI test increased, and as the amount of $S$. aureus being shed increased. Quarters that cultured positive multiple times before drying-off were less likely to cure. Staphylococcus aureus infections located in front quarters of the udder were 2 times more likely to cure than those in hind quarters. Results of this study demonstrate that intramammary tilmicosin at drying-off is efficacious in curing existing $S$. aureus during the dry period. Risk factors associated with the cure of $S$. aureus were identified.

(Key words: Staphylococcus aureus, dry cow therapy, tilmicosin)

Received January 5, 2002.

Accepted April 9, 2002.

Corresponding author: R. T. Dingwell; e-mail: rdingwell@vet. k-state.edu.
Abbreviation key: CNS = coagulase-negative staphylococci, $\mathbf{C P 5}$ = capsular polysaccharide 5, DCT = dry cow antibiotic therapy, $\mathbf{L S}=$ linear score, $\mathbf{O R}=$ odds ratio.

\section{INTRODUCTION}

The goal of mastitis control during the dry period is to have as few infected quarters as possible at the next calving (Eberhart, 1986). Achieving this goal involves eliminating existing IMI present at the end of lactation, as well as preventing new IMI during the dry period. At present, the most effective means of achieving these objectives is to administer long-acting dry cow antibiotic therapy (DCT) immediately after the last milking (Eberhart, 1986). The use of DCT can reduce the incidence of new IMI by 50 to $75 \%$. This reduction in IMI is more pronounced early than later in the dry period (Smith et al., 1985). In addition, approximately 70 to 98\% of infections present at drying-off are eliminated during the dry period following DCT (Natzke, 1981; Smith et al., 1985). However, compared with elimination of other pathogens, DCT is generally acknowledged as being less successful in eliminating IMI caused by Staphylococcus aureus. The cure rate of $S$. aureus has been reported to be approximately 50\% (Browning et al., 1990; Osteras et al., 1994, 1999). Despite this average, actual cure rates of $S$. aureus may vary between 20 to 78\% (Cummins and McCaskey, 1987; Erskine et al., 1994; Nickerson et al., 1999; Soback et al., 1990; Sol et al., 1994).

With very few exceptions, cure of major mastitis pathogens following DCT is not likely a random event. Variation in cure rate may be explained by pathogen, cow, and herd factors. It would be of considerable importance to the dairy industry to be able to predict which cows were more likely to cure (Schukken et al., 2001). In an attempt to augment the effectiveness of DCT, various protocols and products have been tested (So- 
back et al., 1990; Hogan et al., 1995; Erskine et al., 1998; Nickerson et al., 1999). One such treatment that has recently been investigated is the use of tilmicosin.

Tilmicosin is a semisynthetic macrolide antibiotic, currently approved for the treatment of bovine respiratory disease. This drug possesses properties that might prove favorable in combatting dry period IMI, especially subclinical $S$. aureus infections. These properties include the observed in vitro interactions of the antibiotic with bovine phagocytes and epithelial cells (Scorneaux and Shryock, 1999). Tilmicosin is rapidly accumulated in bovine macrophages and mammary epithelial cells. The uptake in mammary gland cells is dependent on cell viability, temperature, and $\mathrm{pH}$, but is not influenced by either metabolic inhibitors or an anaerobic environment (Scorneaux and Shryock, 1999).

In recently published research, tilmicosin was compared to intramammary cephapirin benzathine as a treatment of $S$. aureus at dry-off (Nickerson et al., 1999). The tilmicosin was either administered intramammary (1500 mg) or via a subcutaneous injection at $5 \mathrm{mg} / \mathrm{kg}$ of BW on the day of drying-off, and again $4 \mathrm{~d}$ later. The reported quarter cure rates for IMI caused by $S$. aureus at $28 \mathrm{~d}$ post calving were: $78.1 \%$ intramammary cephapirin, $74.2 \%$ intramammary tilmicosin, and 9.1\% subcutaneous tilmicosin. Intramammary tilmicosin was concluded to be as effective as cephapirin benzathine.

In addition to new treatment regimes, considerable attention has been concentrated on identifying specific risk factors that influence the cure of $S$. aureus, such that DCT might be specifically aimed at only those cows with a high probability of cure (Sol et al., 1994). This implies that a manager would have to decide to remove cows from the herd that have a low probability of cure. There are significant quarter level and cow level predictors for cure of $S$. aureus. Cure rate has been shown to be strongly influenced by the location of the infected quarter in either the front of the hind of the udder, the age of the cow, the percentage of samples that were culture positive for $S$. aureus before drying-off, the SCC of infected quarters and the total number of quarters that are infected (Sol et al., 1994; Osteras et al., 1999).

The efficacy of intramammary tilmicosin to eliminate $S$. aureus has recently been reported from data collected in two herds, with the majority of cows having experimental infections (Nickerson et al., 1999). The objective of this paper is to present the results of a DCT field trial that evaluated the efficacy of intramammary tilmicosin phosphate to eliminate naturally occurring $S$. aureus, and identified risk factors associated with achieving cure of subclinical $S$. aureus IMI during the dry period.

\section{MATERIALS AND METHODS}

\section{Herd Selection}

For a period of 1 yr, beginning in July 1999, cows in 75 commercial and two research dairy herds located in three eastern Canadian provinces participated in the field trial [Ontario $(\mathrm{n}=39)$, Quebec $(\mathrm{n}=34)$, Prince Edward Island $(n=4)]$. Herds were selected based on proximity to the veterinary college in their province, to allow for weekly visits by a trained technician. Herd size ranged from 27 to 168 cows with an average of 64 cows. Cows that had not received antibiotic treatment in the last $3 \mathrm{wk}$ and that were 1 mo from the time of scheduled drying-off were eligible for enrollment. The range of prevalance of $S$. aureus in these herds was 0 to $36 \%$ of cows. Data from only those cows that had at least one quarter infected with $S$. aureus are reported in this paper, to discuss the efficacy of intramammary tilmicosin against, and risk factors associated with, cure of $S$. aureus. All other cows in these herds were also randomized to treatment schedules, which formed the basis of other experiments to document the infection status of cows at drying-off and freshening, elimination of pathogens other than $S$. aureus, and the incidence of new IMI during the dry period.

\section{Sampling Time Line and Treatment Randomization}

A study technician collected quarter milk samples aseptically from all eligible cows starting between 28 (d -28) and $22(\mathrm{~d}-22) \mathrm{d}$ before scheduled drying-off, and again between $21(\mathrm{~d}-21)$ and $14(\mathrm{~d}-14) \mathrm{d}$ before drying-off. Drying-off date was calculated to ensure cows would have a minimum 60-d dry period for residue avoidance concerns. Cows that had at least one quarter that yielded $\geq 1 \mathrm{cfu}$ per $0.01 \mathrm{ml}$ of milk of $S$. aureus on either of these first two samples, were defined as infected. These cows were sampled for a third time at drying-off ( $\mathrm{d} 0$ ) and randomly assigned to receive, in all four quarters, either intramammary benzathine cloxacillin (Dry Clox, Ayerst Laboratory, Guelph, Ontario) or a novel intramammary formulation of tilmicosin phosphate (supplied by Provel, Division of Eli Lilly Canada Inc., Guelph, Ontario, Canada). The intramammary infusion of DCT was done by the technician as soon as possible after the last milking, and was administered by the partial insertion technique. Following the subsequent calving, all cows were sampled three times during the first month of lactation at 3 to 9,10 to 16 , and 24 to 30 DIM. Quarters that were infected before the dry period were considered to be cured if they were culture negative for $S$. aureus on all three samples taken in the first month of lactation. A cow was 
defined as cured if all infected quarters before drying-off were culture negative on all three samples after freshening.

\section{Herd Management and Other Data Collection}

During one of the scheduled visits to each farm, the technician at each site administered a comprehensive herd survey. Data collected included housing style, milking hygiene practices, management of the environment for both lactating and dry cows, as well as routine drying-off procedures used by each individual farm. Management factors used to determine appropriate drying-off time, and specific practices such as abrupt versus intermittent cessation of milking, gram-negative core-antigen vaccination, and teat-end protection were collected. Individual cow DHI data for the last three DHI tests before and including the month of drying-off, were collected. The data consisted of dry period length, SCC, linear score (LS), 305 mature equivalent milk, and 24-h yields of milk, fat and protein.

\section{Bacteriological Procedures}

Teats were aseptically prepared before collection of all samples according to National Mastitis Council sample collection and handling guidelines (NMC, 1999). Samples were frozen and shipped to the Mastitis Research Laboratory at the University of Guelph. All laboratory procedures were performed by the same individuals, who were blinded to treatment, and in accordance with NMC recommendations (NMC, 1999). Briefly, depending on the day of arrival at the lab, samples were either thawed at room temperature or stored at $-20^{\circ} \mathrm{C}$ for a period of not longer than $5 \mathrm{~d}$, and then thawed the first day of the following week. An inoculum of $0.01 \mathrm{ml}$ of milk was plated onto Columbia base agar containing 5\% sheep blood. Plates were incubated at $37^{\circ} \mathrm{C}$ and examined for bacterial growth at 24 and $48 \mathrm{~h}$. Colonies were tentatively identified, and a presumptive diagnosis of staphylococci, streptococci, coliform, or other pathogens was made, based on colony growth, morphology and appearance, pattern of hemolysis, catalase reaction, and Gram staining. Staphylococcal isolates were tested for coagulase production with the tube coagulase test. Streptococcal isolates were further subcultured with agar containing esculin. Gram-negative bacteria were plated on MacConkey agar to facilitate identification. Gross appearance and reaction to citrate were used to differentiate Escherichia coli and Klebsiella spp. For each positive quarter, the number of cfu per $0.01 \mathrm{ml}$ of milk was reported in one of four categories: 1 to 5,6 to 10,11 to 50 or $\geq 50 \mathrm{cfu}$. A quarter was considered infected with coagulase-negative staphylo- cocci $(\mathbf{C N S})$ if greater than or equal to $11 \mathrm{cfu}$ per 0.01 $\mathrm{ml}$ were isolated. The isolation of CNS was reported when the organism grew with another pathogen. A sample was considered contaminated if three or more colony types were present on a plate. Since all samples were frozen, quarter SCC determination was not performed.

\section{Statistical Analysis}

Data generated from the quarter milk cultures, herd management surveys and individual cow DHI records, were stored in a Microsoft Access database (Microsoft Access 2000). Only those herds that participated in the trial for its entire length, and that had $S$. aureus isolated from at least one cow during that time, provided the data analyzed in this study. Records for 308 quarters infected with $S$. aureus from 219 cows on 59 farms were extracted from the database and imported into SAS version 8.01 (SAS, 1999). There were 18 farms in which cows infected with $S$. aureus were either not identified, or cows were identified but they did not complete the trial. Descriptive statistics were generated using the univariate and frequency procedure in SAS (PROC UNIVARIATE, PROC FREQ, SAS v.8.01). Differences in cure rates were tested with a chi-square $\left(\chi^{2}\right)$ analysis. Least square means for linear scores $(\mathbf{L S})$ at drying-off were calculated (PROC GLM) and differences examined using a Student's $t$-test. Logistic regresion for cure or no cure of $S$. aureus infection was modeled by fitting a generalized linear model using the GENMOD procedure, with the logit link function, and a binomial error distribution. Because quarters within a cow are not independent, correlation within cows was accounted for using generalized estimation equations (Liang and Zeger, 1986; Barkema, 1997). A compound symmetry correlation structure was used. Data were analyzed by quarter, cow, and herd levels, acknowledging that there was clustering of quarters within a cow, as well as of cows within a herd. The variance components at both the herd and cow level were evaluated to decide whether cow and herd effects would be considered as either random or fixed effects in the final model. Since herds had a very low variance component, the most appropriate and best fitting model included herd as a fixed effect and cows within herds as a clustering variable. In fitting herds as a fixed effect, a herd size variable was created to identify each herd that had more than 100 cows. This allowed comparison between these herds, as well as to those that were smaller in size. This distinction was necessary, as the model did not converge when a parameter was estimated for each individual herd. The choice of herd size was based on inherent differences in management strategies and housing styles associated with larger herds. 
A variable to quantify the degree of shedding was created using the reported colony-forming units on each positive sample. The original results from the laboratory were reported in categories, thus the variable created was categorical. A bacteriology result of 1 to $5 \mathrm{cfu}$ was given a code of $1,6-10 \mathrm{cfu}$ a code of $2,11-50 \mathrm{cfu}$ coded 3 , and greater than 50 cfu coded 4 . Hence, if a cow had three positive samples that were coded 3,3 , and 4 , the shedding code assigned to that cow was 10 . To assess the effect that the month of drying-off had on the cure rate, a season variable was created using 3-mo intervals. Spring was designated as March-May, Summer as June-August, Fall as September-November, and winter included December to February. A univariate model with each independent variable of interest was evaluated first, with all significant variables at $P<0.20$ allowed to enter the multivariable model. Relaxing the $P$ value for entry into the model was used as a method to ensure all covariates, with a potential to exert significant main effects as well as important confounding effects, were considered. A backwards step-wise procedure was used to determine the final model. Statistical significance was declared at $P<0.05$, but variables with $\mathrm{P}<0.10$ were allowed to stay in the model based on a tendency towards significance, and if these associations were deemed to be of biological importance. All biologically plausible two-way interactions were tested. The estimated regression parameters were converted to odds ratios.

\section{RESULTS}

The total number of cows dried off that were defined as infected with $S$. aureus positive was 288 . The percentage of quarter samples that were contamined was $13.5 \%$. After excluding cases where protocol was not followed or cows were lost to follow-up sample collection, (samples not taken, cows having received other antibiotic treatment, cows aborting in the dry period or having been sold), as well as excluding all contaminated quarters, 219 cow records, representing 308 infected quarters, were available for analysis of treatment efficacy and risk factors for elimination of $S$. aureus infection. Complete DHI records were not available for all 219 cows, as some herds did not subscribe to this milk recording service. Descriptive data pertaining to the infected quarters and cows are presented in Tables 1 and 2 . Of the $219 \mathrm{~S}$. aureus positive cows, 154 (70.3\%) had only one quarter infected. The percentage with two, three, or four infected quarters were 21.5, 5.5, and 2.7\%, respectively. The average LS as reported on the last DHI test in the month of drying-off was 5.3. There was a significant difference in the mean LS of cows based on the number of quarters infected (Table 1). A calcual- tion of the mean prevalence of $S$. aureus within herds was made, by using the number of cows identified as infected in a herd divided by the total herd size. The mean was found to be $7 \%$ in the 59 herds with a range of 1.2 to $36 \%$.

The majority (58\%) of the 308 quarters identified as infected cultured positive on all three samples taken before drying-off. There was a linear decline in the percentage cure with the number of times a quarter cultured positive (Figure 1). The cure rate for quarters that cultured positive on one sample was significantly higher than quarters that cultured positive multiple times. The distribution of the location of the infected quarters was approximately equal between front and hind quarters (47 and 53\%, respectively).

The overall cure of $S$. aureus after DCT was 136 of the 219 cows $(62 \%)$, and 208 of the 308 quarters $(67.5 \%)$. The cure rates achieved with intramammary tilmicosin was $67.3 \%$ of cows and $72.5 \%$ of quarters (Table 2). By comparison, the cure achieved with intramammary cloxacillin was $56.9 \%$ of cows and $62.9 \%$ of quarters. The results of unconditional univariate analysis determined that this difference in cure rates between treatments was not statistically significant at the $P<0.05$ level for either cow or quarter cure rates (Table 2).

Cure rates were seen to be higher in cows that were finishing their first lactation, that had a LS of less than 5 on their last DHI test. There was a statistically significant difference in the cure rate based on LS on last DHI test: $70.9 \%$ of cows cured that were at $\mathrm{LS}<5$, compared with $56.4 \%$ that were at $\mathrm{LS} \geq 5(P<0.05)$. The highest cure rate was observed in cows that had three quarters infected (83.3\%). The percentage of cows that cured with one, two, or four quarters infected were $65.6,46.8$, and $50 \%$, respectively (Table 2 ).

\section{Logistic Regression Analysis}

Quarter level. The logistic regression model for cure of quarters is shown in Table 3 . Variables predicting the probability of bacteriologic cure in an infected quarter included the number of samples that cultured positive, location of the quarter and the use of tilmicosin DCT (Table 2). The fixed effect herd size variable was forced into the final model. When accounting for the other variables in the model, the use of tilmicosin DCT resulted in a higher probability for cure of $S$. aureus $(P=$ 0.04). The odds ratio (OR) for cure comparing tilmicosin DCT to cloxacillin was 1.8 . The probability of cure increased when the infection was in a front quarter (OR $=2.3$. There was a decreased risk of cure with an increasing number of positive samples before drying-off $(\mathrm{OR}=0.6)$. A higher LS, based on DHI testing at the cow level, tended to decrease the probability of cure at 
Table 1. Descriptive data of cows and quarters infected with Staphylococcus aureus prior to drying-off.

\begin{tabular}{|c|c|c|}
\hline Category & Quarters & Cows \\
\hline Observations (no.) & 308 & 219 \\
\hline \multicolumn{3}{|l|}{$\begin{array}{l}\text { Times an individual quarter cultured } \\
\text { positive prior to drying-off (no.) }\end{array}$} \\
\hline 1 & $62(20.1 \%)$ & \\
\hline 2 & $67(21.8 \%)$ & \\
\hline 3 & $179(58.1 \%)$ & \\
\hline \multicolumn{3}{|l|}{ Quarter location } \\
\hline Front & $145(47 \%)$ & \\
\hline Hind & $163(53 \%)$ & \\
\hline \multicolumn{3}{|l|}{ Isolation of $\mathrm{CNS}^{1}$ as well as } \\
\hline S. aureus in the same quarter sample & $11(3.6 \%)$ & \\
\hline \multicolumn{3}{|l|}{ Quarters infected per cow dried off (no.) } \\
\hline 1 & & $154(70.3 \%)$ \\
\hline 2 & & $47(21.5 \%)$ \\
\hline 3 & & $12(5.5 \%)$ \\
\hline 4 & & $6(2.7 \%)$ \\
\hline Mean lactation (range) & & $2(1-9)$ \\
\hline Parity 1 & & $63(28.8 \%)$ \\
\hline Parity 2 & & $57(26 \%)$ \\
\hline Parity 3+ & & $99(45.2 \%)$ \\
\hline \multicolumn{3}{|l|}{ Mean $\mathrm{LS}^{2}$ last DHI test $(95 \% \mathrm{CI})$ : } \\
\hline \multicolumn{3}{|l|}{$\begin{array}{l}\text { Overall and by the number of } \\
\text { quarters infected with } S \text {. aureus }\end{array}$} \\
\hline Overall & & $5.3(5.1-5.5)$ \\
\hline $1 \mathrm{qtr}$ & & $5.1^{\mathrm{a}}(4.8-5.3)$ \\
\hline $2 \mathrm{qtr}$ & & $5.7^{\mathrm{b}}(5.4-6.1)$ \\
\hline $3 \mathrm{qtr}$ & & $5.9^{\mathrm{abc}}(4.8-6.9)$ \\
\hline $4 \mathrm{qtr}$ & & $6.8^{\mathrm{c}}(5.8-7.7)$ \\
\hline
\end{tabular}

${ }^{\mathrm{a}, \mathrm{b}, \mathrm{c}}$ Means with different superscripts are significantly different at $P<0.05$.

${ }^{1} \mathrm{CNS}=$ Coagulase-negative staphylococci.

${ }^{2} \mathrm{LS}=$ Linear SCC.

Table 2. Descriptive results of the effect of parity, number of quarters infected, $\mathrm{LS}^{1}$ on the lst DHI test, and treatment on cure of Staphylococcus aureus in 219 cows and 308 quarters.

\begin{tabular}{|c|c|c|c|c|c|}
\hline \multirow[b]{2}{*}{ Factor } & \multirow[b]{2}{*}{ Total } & \multicolumn{2}{|c|}{ Cure (cow) } & \multicolumn{2}{|c|}{ Cure (qtr) } \\
\hline & & No. & $\%$ & No. & $\%$ \\
\hline \multicolumn{6}{|l|}{ Parity } \\
\hline 1 & 63 & 42 & $(66.7 \%)$ & & \\
\hline 2 & 57 & 34 & $(59.7 \%)$ & & \\
\hline $3+$ & 99 & 60 & $(60.6 \%)$ & & \\
\hline \multicolumn{6}{|c|}{ Quarters infected $^{2}$} \\
\hline 1 & 154 & 101 & $(65.6 \%)$ & & \\
\hline 2 & 47 & 22 & $(46.8 \%)$ & & \\
\hline 3 & 12 & 10 & $(83.3 \%)$ & & \\
\hline 4 & 6 & 3 & $(50 \%)$ & & \\
\hline \multicolumn{6}{|c|}{$\mathrm{LS}^{1}$ at Drying-off } \\
\hline$<5$ & 86 & 61 & $(70.9 \%)^{\mathrm{a}}$ & & \\
\hline$\geq 5$ & 133 & 75 & $(56.4 \%)$ & & \\
\hline \multicolumn{6}{|c|}{ Intramammary $\mathrm{DCT}^{3}-\mathrm{qtr}$} \\
\hline Tilmicosin & 149 & & & 108 & $(72.5 \%)^{b}$ \\
\hline Cloxacillin & 159 & & & 100 & $(62.9 \%)$ \\
\hline \multicolumn{6}{|c|}{ Intramammary $\mathrm{DCT}^{3}-\mathrm{cow}$} \\
\hline Tilmicosin & 110 & 74 & $(67.3 \%)$ & & \\
\hline Cloxacillin & 109 & 62 & $(56.9 \%)$ & & \\
\hline
\end{tabular}

${ }^{\mathrm{a}} P<0.05$

${ }^{\mathrm{b}} P<0.10$.

${ }^{1} \mathrm{LS}=$ Linear SCC.

${ }^{2}$ Quarters infected $=$ number of quarters per cow defined as positive for $S$. aureus before drying-off.

${ }^{3} \mathrm{DCT}=$ Dry cow antibiotic therapy. 


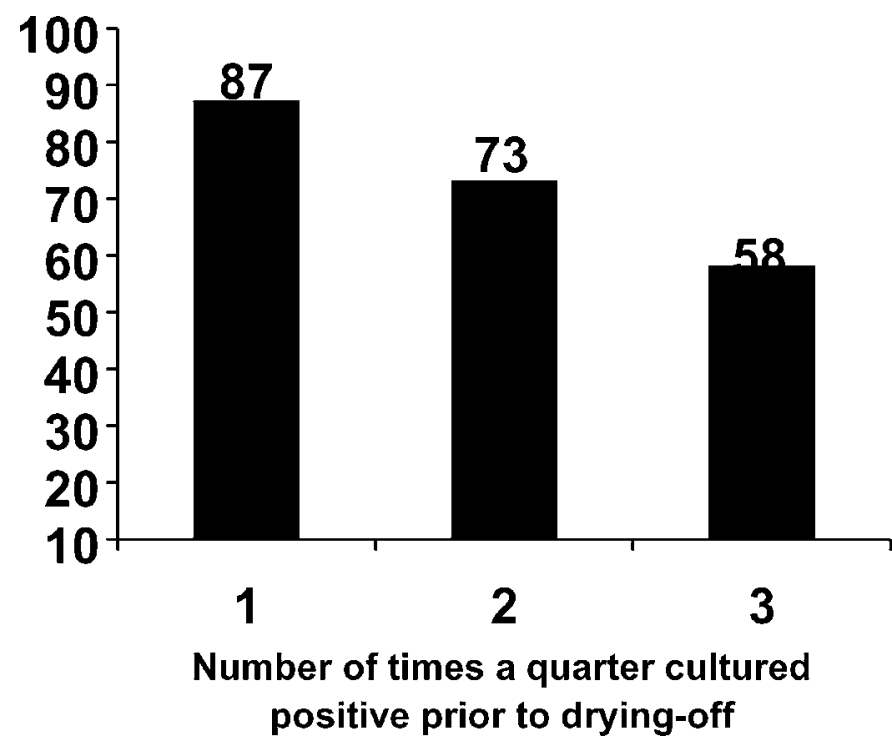

Figure 1. Percentage cure of quarters infected with Staphylococcus aureus during the dry period, relative to the number of times that the quarter cultured positive prior to drying-off.

the quarter level $(P=0.08)$. LS was a significant risk factor for cow level cure $(P=0.05)$. The presence of a CNS infection in the same quarter infected with $S$. aureus was associated with a much higher OR for cure (5.1). The effect was nonsignificant but may be biologically important due to its magnitude. The goodness of fit of the model was assessed by the departure of the model deviance from the degrees of freedom. The deviance of this final model is 308 with $289 \mathrm{df}$, which indicated acceptable fit.

Cow level. The logistic regression model for cure of cows is shown in Table 4. Risk factors for bacteriological cure of cows included LS on the last DHI test, bacterial shedding, season of drying-off, as well as intramammary treatment with tilmicosin. At the cow level, intramammary tilmicosin remained a significant factor in the model $(P=0.03)$. A cow treated with tilmicosin has a 2.1 times greater chance of curing $S$. aureus, compared with a cow treated with cloxacillin. The variable 'shedding' was significant $(P=0.0002)$, indicating that as the degree of $S$. aureus shed increased, the probability of cure decreased. Clearly, an equivalent shedding variable could be generated from large numbers of bacteria shed from one quarter or from moderate numbers shed from multiple quarters. Therefore, the interaction of shedding and number of infected quarters was tested and found to be significant $(P=0.002)$. This interaction indicated that lower shedding per infected quarter had a somewhat better probability of cure. There was a significant effect, at the cow level, for season to impact the probability of cure. In comparison to cows that were dried off in the spring season (March-May), cows that were dried off during the winter (December-February) were 4 times more likely to cure $S$. aureus infection $(P$ $=0.004)$. Age of the cow and dry period length were not significant risk factors for $S$. aureus cure either at the quarter or cow level. With $198 \mathrm{df}$ and a deviance of 221 , the fit of the model was acceptable.

\section{DISCUSSION}

Administration of DCT at the end of lactation remains one of the cornerstones of an udder health management program. Previous research has demonstrated that the dry period represents a time of increased susceptibility to new IMI and that DCT can eliminate and prevent new infections during this time. However, the

Table 3. Results of final logistic regression model for the probability of cure of quarters infected with Stapylococcus aureus during the dry period.

\begin{tabular}{|c|c|c|c|c|c|c|}
\hline \multirow[b]{2}{*}{ Intercept } & \multirow{2}{*}{$\frac{\beta \text { estimate }}{2.4595}$} & \multirow{2}{*}{$\frac{\mathrm{SE}}{0.74}$} & \multicolumn{2}{|c|}{$\begin{array}{c}\text { Wald } 95 \% \text { confidence } \\
\text { limits }\end{array}$} & \multirow{2}{*}{$\frac{P \text {-value }}{0.0008}$} & \multirow[t]{2}{*}{ Odds ratio } \\
\hline & & & 1.015 & 3.904 & & \\
\hline $\begin{array}{l}\mathrm{LS}^{2} \text { at Dry-off } \\
\mathrm{DCT}^{3}\end{array}$ & -0.1968 & 0.11 & -0.419 & 0.025 & 0.08 & 0.8 \\
\hline $\begin{array}{l}\text { Tilmicosin } \\
\text { Cloxacillin }\end{array}$ & 0.6190 & 0.29 & 0.03 & 1.203 & 0.04 & 1.8 \\
\hline Front Quarter & 0.8429 & 0.24 & 0.373 & 1.313 & 0.0004 & 2.3 \\
\hline No. cultures positive $e^{4}$ & -0.4615 & 0.20 & -0.847 & -0.077 & 0.02 & 0.6 \\
\hline CNS infection ${ }^{5}$ & 1.6447 & 0.93 & -0.171 & 3.460 & 0.08 & 5.1 \\
\hline
\end{tabular}

${ }^{1}$ Fixed effect of herds forced into the model.

${ }^{2} \mathrm{LS}=$ Linear SCC.

${ }^{3} \mathrm{DCT}=$ Dry cow antibiotic therapy.

${ }^{4}$ Number of quarter cultures prior to drying-off from which $S$. aureus was isolated.

${ }^{5} \mathrm{CNS}$ infection $=>10 \mathrm{cfu} / 0.01 \mathrm{ml}$ milk coagulase negative staphylococci isolated from same quarter as $S$. aureus. 
Table 4. Results of final logistic regression model for the probability of cure of cows infected with Staphylococcus aureus during the dry period.

\begin{tabular}{|c|c|c|c|c|c|c|}
\hline \multirow[b]{2}{*}{ Intercept } & \multirow{2}{*}{$\begin{array}{c}\beta \text { estimate } \\
3.4579\end{array}$} & \multirow{2}{*}{$\frac{\mathrm{SE}}{1.13}$} & \multicolumn{2}{|c|}{$\begin{array}{c}\text { Wald } 95 \% \text { confidence } \\
\text { limits }\end{array}$} & \multirow{3}{*}{$\frac{P \text {-value }}{0.002}$} & \multirow[t]{2}{*}{ Odds ratio } \\
\hline & & & 1.249 & 5.666 & & \\
\hline Herds $^{1}$ & & & & & & \\
\hline $\begin{array}{l}\mathrm{LS}^{2} \text { at Dry-off } \\
\mathrm{DCT}^{3}\end{array}$ & -0.2406 & 0.12 & -0.482 & 0.0005 & 0.05 & 0.78 \\
\hline Tilmicosin & 0.7522 & 0.35 & 0.066 & 1.438 & 0.03 & 2.1 \\
\hline Cloxacillin & $\ldots$ & $\ldots$ & $\ldots$ & $\ldots$ & $\ldots$ & \\
\hline Season of dry-off & & & & & & \\
\hline Summer & 0.8299 & 0.47 & -0.100 & 1.76 & 0.08 & \\
\hline Fall & 0.6504 & 0.43 & -0.185 & 1.486 & 0.13 & \\
\hline Winter & 1.4880 & 0.52 & 0.479 & 2.498 & 0.004 & 4.4 \\
\hline Spring & & & & & & \\
\hline Shedding $(\mathrm{CFU})^{4}$ & -0.3275 & 0.09 & -0.501 & -0.154 & 0.0002 & 0.72 \\
\hline No. Quarters Positive ${ }^{5}$ & -0.3971 & 0.56 & -1.498 & 0.704 & 0.48 & \\
\hline$(\text { Shedding)*(No. Qtr. })^{6}$ & 0.0832 & 0.03 & 0.031 & 0.136 & 0.002 & \\
\hline
\end{tabular}

${ }^{1}$ Fixed effect of herd forced into the model.

${ }^{2} \mathrm{LS}=$ Linear SCC.

${ }^{3} \mathrm{DCT}=$ Dry cow antibiotic therapy.

${ }^{4}$ Variable created to assess the amount of colony forming units of S. aureus shed.

${ }^{5}$ Number of quarters from which $S$. aureus was isolated in a cow.

${ }^{6}$ Interaction term of shedding by the number of quarters positive.

rate of elimination of existing $S$. aureus mastitis following DCT at the end of lactation is variable. Tilmicosin phosphate is a semisynthetic macrolide antibiotic, which has been shown to have important interactions with bovine phagocytes and epithelial cells, demonstrating a potential role in its clinical efficacy against intracellular organisms. One mechanism, beleived to aid in $S$. aureus evasion of cure during DCT, is by the intracellular accumulation of $S$. aureus within phagocytes. Hensen et al. (2000) recently studied the location of $S$. aureus after experimental infection, both by gram staining and immunochemical staining of tissues with antibodies against capsular polysaccharide 5 (CP5). In both early and chronic stages of these infections, $S$. aureus was located in the lumen of alveoli, associated with epithelium, and within phagocytic cells. It was concluded that invasion by $S$. aureus of the interstitium, as well as expression of CP5, augment its resistance to host defense mechanisms. Likewise, Nickerson and Heald (1981) demonstrated that both under natural chronic infection, and in experimental infections, $S$. aureus could be observed in neutrophils or macrophages. Therefore, if an intramammary DCT product had the ability to be accumulated within these same cells, an improved efficacy against mastitis caused by $S$. aureus may be attainable.

Benzathine cloxacillin was used as the positive control in this field trial, as it has been commercially available and used for approximately $20 \mathrm{yr}$ (Keefe, 1980). Cloxacillin is a semisynthetic penicillin. When it was first evaluated as a DCT, the rates of elimination of $S$. aureus when administered at drying-off were 85 and $77 \%$ in controlled and field trial experiments, respectively. One year later, Ziv et al. (1981) published efficacy data comparing three antibiotics at drying-off, one of which was a derivative of benzathine cloxacillin. This data revealed a mean cure rate of $S$. aureus from all three treatments during the dry period of $81.4 \%$. The cure rate for benzathine cloxacillin was $83.1 \%$.

The most recently published efficacy data for the use of tilmicosin at drying-off was reported by Nickerson et al. (1999), who used cephapirin benzathine as a positive control. This study demonstrated that an experimental intramammary formulation of tilmicosin was equally as effective as cephapirin benzathine for eliminating $S$. aureus mastitis at both the cow and quarter levels, with tilmicosin achieving 64.3 and $78.1 \%$ cure rates, respectively. The main difference between Nickerson's study and the current field trial, other than the positive control used, was the nature of the infections. The previously cited numbers were obtained following dry cow therapy of 44 cows, the majority of which had infections that were experimentally induced. The cure rates for both intramammary treatments were consistently higher for experimental infections than those caused naturally (Nickerson et al., 1999). The current study was done in commercial and research farms in three geographical regions of Canada, with cows that were naturally infected, and identified through the culture of quarter milk samples collected prior to drying-off.

An important consideration that must be addressed whenever efficacy data for therapy of mastitis patho- 
gens, especially for cure rates of $S$. aureus, are reported, are the definitions of infection and treatment cure. In this current study, the definition of infection before drying-off was at least one of three samples being culture positive ( $\geq 1 \mathrm{cfu} / 0.01 \mathrm{ml}$ ) for $S$. aureus. Based on the fact that approximately $80 \%$ of the infections in this trial actually cultured positive on multiple samples before drying-off, confidence that these quarters and cows were indeed infected with $S$. aureus seems reasonable. Furthermore, these animals were probably a good representation of naturally infected cows in commercial herds. However, there were $20.1 \%$ of quarters in this dataset that had only a single isolation of $S$. aureus, and there was also an underlying assumption that when $S$. aureus was not isolated, that an infection did not exist. Intermittent and cyclical shedding of $S$. aureus does occur (Sears et al., 1990). Sears et al. (1990) studied the shedding patterns of $S$. aureus and the implication of shedding patterns when evaluating the efficacy of antimicrobial drugs. They concluded that the cyclical pattern of shedding necessitates consecutive samples. The probability of at least one sample being positive from a $S$. aureus-infected quarter when three samples are taken was estimated at $98 \%$ (Sears et al., 1990). Based on this fact, both the definition of infection and the definition of cure in this trial were made on three consecutive samples. The decision to extend the sampling out of 30 DIM in the subsquent lactation was deemed appropriate, by earlier research which established that it may take up to $28 \mathrm{~d}$ for a $S$. aureus infection to reappear (Newbould, 1974). Another more recently identified aspect of $S$. aureus cure and sampling, is the identification of the particular strain of $S$. aureus through DNA technologies (Zadoks, 2000). This technology was not incorporated into this research trial. Thus, there is a possibility that some treatment failures in efficacy trials, such as the current study, may indeed be misclassified and are actually a combination of a cure and a new infection caused by an entirely different strain of the same organism (Schukken et al., 2001).

Regardless of the efficacy of any one treatment regime of therapeutic approach, emphasis should be placed on identifying cows that have a high probability of cure. Because antibiotic use on dairy farms is under increasing scrutiny, considering opportunties for more rational and selective use of DCT is of value (Schukken et al., 2001). The results of this study indicate that risk factors for cure of quarters infected with $S$. aureus are the number of positive cultures, the location of the quarter, and possibly a coexisting CNS infection $(P<0.10) . S$. aureus IMI was less likely to be cured in quarters that were culture positive more than once. Also, cure of $S$. aureus was less likely to occur when the infection was in a rear quarter. These risk factors have been previously reported (Sol et al., 1994; Osteras et al., 1999). Indeed, there is a possibility that the number of positive samples may be a surrogate measure of severity or chronicity. Also there is a possibility that only a single isolation of $S$. aureus may not truly have been an infection. The repeatability of the significance of the location of the quarter is surprising. Osteras et al. (1999) established even more specifically the predictive failure of an infection with a major pathogen in the right hind quarter, not just a hind quarter. The authors hypothesized in that study that more persistent infections in the right hind quarter might result from hygienic contamination caused by laterality or side-specific interference of blood circulation. No information was gathered in this study to refute or support this claim, or to offer any other hypothesis either. The repeatability of this finding however, should be the attention of further work.

The linear score of the cow in the month before drying-off had a tendency to significantly impact the quarter level cure rate $(P=0.08)$. As the linear score increased, the probability for cure of an infected quarter decreased $(\mathrm{OR}=0.8)$. There was no expectation that a cow level measure such as LS would have that strong of an influence at the quarter level. However, this is likely because $70 \%$ of infected cows in this trial only had one quarter infected with $S$. aureus. Similar to the number of positive samples, a high LS is probably indicative of a more severe infection. Sol et al. (1994), also found that an increasing SCC decreased the probability of quarter cure. The other biologically significant finding at the quarter level was the tendency for an existing infection caused by CNS to increase the probability of cure $(P=0.08)$. This finding is based on only a very small number of quarters that had both CNS and $S$. aureus isolated. The literature indicates that minor pathogen infections have a protective effect against the establishment of $S$. aureus infections (Nickerson et al., 1994; Lam et al., 1997; Schukken et al., 1999). Because these infections were identified at the same time as the $S$. aureus, this may not be a readily plausible explanation for the effect seen here. Competition between the two organisms has been described and can result in a shorter duration of $S$. aureus infection (Lam et al., 1997). However, the mechanism producing the protection effect is not fully understood. General activation of the immune system, competition for binding sites and alterations in teat canal keratin are offered as possible explanations (Rainard et al., 1988; Nickerson et al., 1994; Lam et al., 1997).

Risk factors for cure of cows infected with $S$. aureus included LS on the last DHI test before drying-off and the amount of bacteria being shed by the cow. As LS and the amount of bacteria shed increase, the likelihood of a cure diminished. The other factor found to be sig- 
nificantly associated with the cure rate of $S$. aureusinfected cows in this research was the season of dryingoff. Cows dried off from December to February had a significantly higher cure rate. Biologically satisfying reasons for this effect are not apparent. There was not a significant association with the number of quarters positive for $S$. aureus, as a determinant on its own. However, there was an interaction between the number of quarters and shedding, and as reported in Table 2, the highest proportion of cure was observed in the 12 cows that had three quarters infected (83.3\%). However, Sol et al. (1994) reported that cows with more than one quarter infected were 0.57 times less likely to cure. Our result is similar to the finding of Nickerson et al. (1999), who also reported that cure rates for intramammary tilmicosin were not influenced by either the number of quarters infected or by the lactation number. There was also no association between the probability of cure and dry period length. A positive correlation between a SCC measure and dry period length can reduce the effect of both variables individually (Sol et al., 1994). LS on the last DHI test was significant in the model for cure at the cow level. Thus, the finding that dry period was not a risk factor may be reasonable since these two variables were moderately correlated in this data $(\mathrm{r}=0.56)$.

\section{CONCLUSIONS}

The results of this field trial, conducted in 75 commercial and two research dairy farms, demonstrate that intramammary tilmicosin was efficacious in eliminating existing $S$. aureus mastitis during the dry period. Signficiant risk factors were identified that were associated with bacteriological cure. Quarters that were culture positive more than once, and that were located in the rear of the udder, were less likely to cure. Significant factors for cow cure rates were low LS in the month prior to drying-off, and shedding low numbers of bacteria. This study has demonstrated the efficacy of a new antibiotic as a dry cow therapeutic product in the struggle against $S$. aureus mastitis. At present, an intramammary formulation of tilmicosin for therapy of cows at drying-off is not available. Of equal importance to choosing the appropriate product, is the identification of risk factors which can aid in the decision of which cows can be expected to respond favorably to dry cow antibiotic therapy. This study confirmed the usefulness of LS before drying-off, culture history, and the location of $S$. aureus infection, for incorporation into mastitis control and therapy decision-making processes.

\section{ACKNOWLEDGMENTS}

The author's gratefully acknowledge the dedication of the research technicians at each site: Jeromy TenHag,
Theresa Rogers, Isabelle Dutil, Angela Fairfield and Alana McNicholl. A special thanks to the producers who participated, as well as Anna Bashiri and the staff at the Mastitis Research Laboratory. Thanks also to Gord Vessie for monitoring the trial, and Dr. Emile Bouchard and Dr. Marie-Anne Paradis for their involvement. This study was supported financially by Provel (a Division of Eli Lilly Inc. Canada), the Dairy Farmers of Ontario, and the Ontario Ministry of Agriculture, Food and Rural Affairs.

\section{REFERENCES}

Barkema, H. W., D. T. Galligan, Y. H. Schukken, T. J. G. M. Lam, M. L. Beiboer, and A. Brand. 1997. Estimation of interdepenence among quarters of the bovine udder with subclinical mastitis and implications for analysis. J. Dairy Sci. 80:1592-1599.

Browning, J. W., G. A. Mein, M. Barton, T. J. Nicholls, and P. Brightling. 1990. Effect of antibiotic therapy at drying-off on mastitis in the dry period and early lactation. Aust. Vet. J. 67:440-442.

Cummins, K. A., and T. A. McCaskey. 1987. Multiple infusions of cloxacillin for treatment of mastitis during the dry period. J. Dairy Sci. 70:2658-2665.

Eberhart, R. J. 1986. Management of dry cows to reduce mastitis. J. Dairy Sci. 69:1721-1732.

Erskine, R. J., P. C. Bartlett, P. C. Crawshaw, and D. M. Gombas. 1994. Efficacy of intramuscular oxytetracycline as a dry cow treatment for Staphylococcus aureus mastitis. J. Dairy Sci. 77:3347-3353.

Erskine, R. J., P. C. Bartlett, S. R. Tavernier, L. H. Fowler, R. D. Walker, J. H. Sequin, and D. Shuster. 1998. Recombinant bovine interleukin-2 and dry cow therapy: Efficacy to cure and prevent intramammary infections, safety, and effect on gestation. J. Dairy Sci. 81:107-115.

Hensen, S. M., M. J. A. M. P. Pavičić, J. A. C. M. Lohuis, J. A. M. de Hoog, and B. Poutrel. 2000. Location of Staphylococcus aureus within the experimentally infected bovine udder and the expression of capsular polysaccharide type 5 in situ. J. Dairy Sci. 83:1966-1975.

Hogan, J. S., K. L. Smith, D. A. Todhunter, and P. S. Schoenberger. 1995. Efficacy of recombinant bovine interleukin-2 as an adjunct to dry cow therapy. J. Dairy Sci. 78:1062-1067.

Keefe, T. J. 1980. Benzathine cloxacillin as a dry-cow mastitis product. Modern Vet. Practice. September: 783-785.

Lam, T. J. G. M., Y. H. Schukken, J. H. van Vliet, F. J. Grommers, M. J. M. Tielen, and A. Brand. 1997. Effect of natural infection with minor pathogens on susceptibility to natural infection with major pathogens in the bovine mammary gland. Am. J. Vet. Res. $58: 17-22$.

Liang, K.-Y., and S. Zeger. 1986. Longitudinal data analysis suing generalized linear models. Biometrika 73:13-22.

National Mastitis Council. 1999. Pages 1-11 and 31-39 in Laboratory Handbook on Bovine Mastitis. rev. ed. Natl. Mastitis Counc., Inc., Madison, WI.

Natzke, R. P. 1981. Elements of mastitis control. J. Dairy Sci. 64:1431-1432.

Newbould, F. H. S. 1974. Antibiotic treatment of experimental Staphylococcus aureus infections of the bovine mammary gland. Can. J. Comp. Med. 38:411-416.

Nickerson, S. C., and C. W. Heald. 1981. Histopathologic response of the bovine mammary gland to experimentally induced Staphylococcus aureus infection. Am. J. Vet. Res. 42:1351-1355.

Nickerson, S. C., and R. L. Boddie. 1994. Effect of naturally occurring coagulase-negative staphylococcal infections on experimental challenge with major mastitis pathogens. J. Dairy Sci. $77: 2526-2536$.

Nickerson, S. C., W. E. Owens, L. K. Fox, C. C. Scheifinger, T. R. Shryock and T. E. Spike. 1999. Comparison of tilmicosin and 
cephapirin as therapeutics for Staphylococcus aureus mastitis at dry-off. J. Dairy Sci. 82:696-703.

Østeras, O., L. Sandvik, J. Aursjo, G. G. Gjul and A. Jorstad. 1994. Effect of dry cow therapy on subclinical mastitis—an evaluation of long-acting and short acting injectors. J. Vet. Med. B.41:529-540.

Østeras, O., V. L. Edge, and S. W. Martin. 1999. Determinants of success or failure in the elimination of major mastitis pathogens in selective dry cow therapy. J. Dairy Sci. 82:1221-1231.

Rainard, P., and Bernard Poutrel. 1988. Effect of naturally occurring intramammary infections by minor pathogens on new infections by major pathogens in cattle. Am. J. Vet. Res. 49:327-329.

SAS User's Guide: Statistics, Release 8.01. 1999-2000. SAS Inst. Inc., Cary, N.C.

Scorneaux, B., and T. R. Shryock. 1999. Intracellular accumulation, subcellular distribution, and efflux of tilmicosin in bovine mammary, blood, and lung cells. J. Dairy Sci. 82:1202-1212.

Schukken, Y. H., K. E. Leslie, D. A. Barnum, B. A. Mallard, J. H. Lumsden, P. C. Dick, G. H. Vessie, and M. E. Kehrli. 1999. Experimental Staphylococcus aureus intramammary challenge in late lactation dairy cows: quarter and cow effects determining the probability of infection. J. Dairy Sci. 82:1-9.
Schukken, Y. H., L. Tikovsky, D. Wilson, and O. Østerås. 2001. Factors affecting the success of antibiotic treatment at dry-off. Pages 80-87 in Natl. Mastitis Counc. Reg. Mtg. Proc., Reno, Nevada. Natl. Mastitis Counc., Inc., Madison, Wisconsin.

Sears, P. M., B. S. Smith, P. B. English, P. S. Herer, and R. N Gonzalez. 1990. Shedding pattern of Staphylococcus aureus from bovine intramammary infections. J. Dairy Sci. 73:2785-2789.

Smith, K. L., D. A. Todhunter, and P. S. Schoenberger. 1985. Environmental pathogens and intramammary infection during the dry period. J. Dairy Sci. 68:402-417.

Soback, S., G. Ziv, M. Winkler and A. Saran. 1990. Systemic dry cow therapy-a preliminary report. J. Dairy Sci. 73:661-666.

Sol, J., O. C. Sampimon, J. J. Snoep, and Y. H. Schukken. 1994 Factors associated with bacteriological cure after dry cow treatment of subclinical Staphylococcal mastitis with antibiotics. J. Dairy Sci. 77:75-79.

Ziv, G., M. Storper, and A. Saran. 1981. Comparative efficacy of three antibiotic products for the treatment and prevention of subclinical mastitis during the dry period. Vet. Q. 3:74-79.

Zadoks, R., Y. H. Schukken, and H. Barkema. 2000. Staphylococcus aureus: Fingerprinting the culprit. Pages 79-93 in Natl. Mastitis Counc. Reg. Mtg. Proc., Atlanta, Georgia. Natl. Mastitis Counc., Inc., Madison, WI. 